\title{
Conversion of fish processing wastewater into fish feed ingredients through submerged cultivation of Aspergillus oryzae
}

\author{
Taner Sar $^{1,2} \cdot$ Jorge A. Ferreira ${ }^{1}$ (D) Mohammad J. Taherzadeh ${ }^{1}$
}

Received: 7 June 2020 / Revised: 15 July 2020 / Accepted: 23 July 2020 / Published online: 30 July 2020

(c) The Author(s) 2020

\begin{abstract}
Fish processing towards production of fillet gives rise to wastewater streams that are ultimately directed to biogas production and/or wastewater treatment. However, these wastewater streams are rich in minerals, fat, and proteins that can be converted to protein-rich feed ingredients through submerged cultivation of edible filamentous fungi. In this study, the origin of wastewater stream, initial $\mathrm{pH}$, cultivation time, and extent of washing during sieving, were found to influence the amount of recovered material from the wastewater streams and its protein content, following cultivation with Aspergillus oryzae. Through cultivation of the filamentous fungus in sludge, $330 \mathrm{~kg}$ of material per ton of COD were recovered by sieving, corresponding to $121 \mathrm{~kg}$ protein per ton of COD, while through its cultivation in salt brine, $210 \mathrm{~kg}$ of material were recovered per ton of COD, corresponding to $128 \mathrm{~kg}$ protein per ton of COD. Removal ranges of $12-43 \%, 39-92 \%$, and 32-66\% for COD, total solids, and nitrogen, respectively, were obtained after $A$. oryzae growth and harvesting in the wastewater streams. Therefore, the present study shows the versatility that the integration of fungal cultivation provides to fish processing industries, and should be complemented by economic, environmental, and feeding studies, in order to reveal the most promising valorization strategy.
\end{abstract}

\section{Graphic abstract}

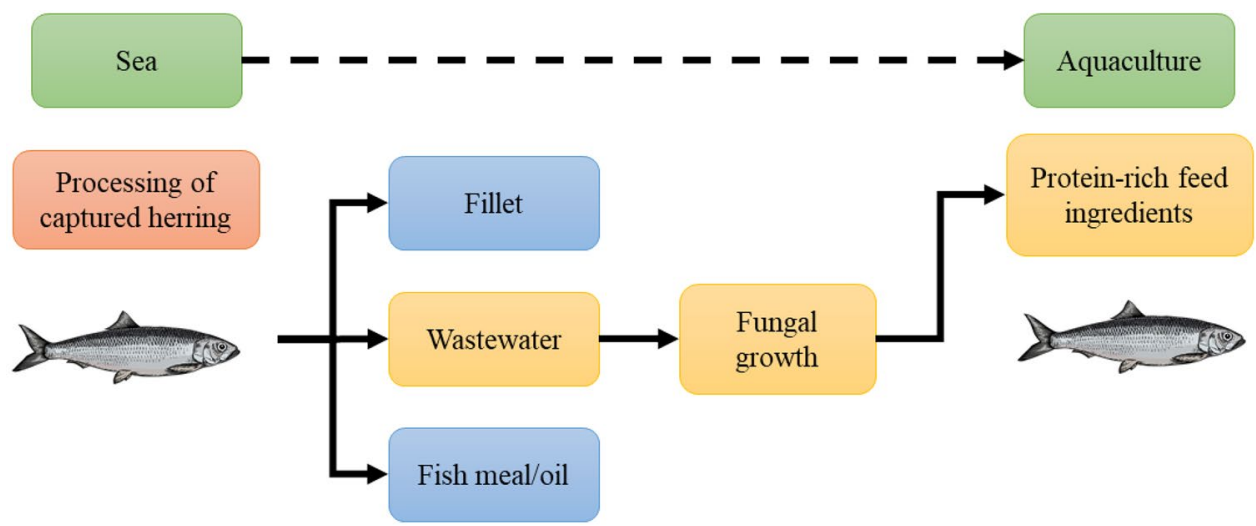

Keywords Aspergillus oryzae · Fish processing wastewater streams · Protein sources · Waste management

Jorge A. Ferreira

Jorge.Ferreira@hb.se

1 Swedish Center for Resource Recovery, University of Borås, 50190 Borås, Sweden

2 Department of Molecular Biology and Genetics, Gebze Technical University, 41400 Gebze-Kocaeli, Turkey

\section{Introduction}

Filamentous fungi contribute to the global economy through production of valuable products such as antibiotics, enzymes, and organic acids [1]. Some filamentous fungal strains have also been used for production of fermented foods for human consumption, hence being considered as Generally Regarded As Safe (GRAS) microorganisms. Examples 
include Aspergillus oryzae for production of miso, Rhizopus oryzae for production of tempe and tofu, Neurospora intermedia for production of oncom, and Fusarium venenatum for production of Quorn ${ }^{\mathrm{TM}}$ products [2]. Therefore, filamentous fungi are taxonomically wide and enzymatically versatile biocatalysts, able to grow on a wide range of substrates and produce various products. Consequently, their investigation in the context of circular bioeconomy, converting nutrients containing low-value substrates into value-added products, has gained momentum over the years. Potential substrates and derived products are wide. The former include lignocellulosic materials, starch- and fat-containing streams, while the latter can include enzymes, alcohols, and fungal biomass $[3,4]$.

Population growth will lead to an increase in the demand of food-producing animals. Hence, finding alternative protein sources for animal feed is currently a hot-topic [5]. Filamentous fungal biomass is normally characterized by high contents of protein contents (40-60\% on a dry weight basis), essential amino acids, polyunsaturated fatty acids, vitamins, chitin/chitosan, and minerals [6]. Accordingly, filamentous fungal biomass has triggered interest in the scientific community for recovery of nutrients in the form of nutritious fungal biomass for use in feed applications [7-9]. In addition to the edible character of some of the strains (e.g. A. oryzae), the interest on the use of filamentous fungi is further reinforced by their growth as macroscopic filamentous structures which can be easily recovered from the medium leaving a stream with a lower organic load [10]. Nonetheless, the composition and concentration of biomass, and type and concentration of additional products produced (e.g. ethanol, organic acids and enzymes), will be influenced by medium composition, physicochemical parameters, and fungal strain $[10,11]$. For instance, a medium with high content of low protein-containing suspended solids can lead to a final fungal biomass with lower protein content due to entanglement of fungal filaments with unconsumed suspended solids [12]. However, in case solid residues are used, this entanglement can lead to an increase in protein content, since e.g. carbohydrates are being replaced by protein-rich fungal biomass, and render the originated product more suitable for feed applications [12]. The fungal strain can influence e.g. the type of nutrients being assimilated, growth rate, growth robustness, and cell wall composition [11]. The latter is of utmost importance in the context of feed applications, since immunostimulant activities have been reported for cell wall components [10]. Altogether, optimization of cultivation conditions in association with low-value streams and fungal strain screening are needed to add definition to the potential of filamentous fungi as alternative source of proteins.

Fish processing industries originate wastewater streams rich in proteins, fat, and minerals. These end normally in separation tanks originating two fractions, namely, sludge, the solid fraction which is directed to biogas production, and wastewater, that follows wastewater treatment $[13,14]$. The nutrients in these streams can alternatively be recovered in the form of nutritious fungal biomass. The latter can be used as fish feed with potential overall positive economic and environmental impact in the sector. Research studies on the conversion of fish processing-derived wastewater streams into protein-rich fungal biomass are scarce in literature, where their inhibitory effect on fungal growth, when used without prior dilution, was found [15]. Accordingly, there is a need to perform a wider screening to identify more robust fungal strains that can offset potential inhibitory effects of fish processing-derived wastewater streams.

The present work investigated the valorization of wastewater streams from herring fish processing industry through cultivation of the edible filamentous fungus $A$. oryzae. Factors studied included wastewater stream origin and concentration, cultivation medium $\mathrm{pH}$, and cultivation medium supplementation. Especial emphasis was given to the amount of harvested material, protein content, and chemical oxygen demand (COD), total solids, and nitrogen removal, following fungal bioconversion and harvesting.

\section{Materials and methods}

\section{Substrate}

Four different herring (Clupea harengus) processing-derived wastewater streams were used in this work and were kindly provided by Scandic Pelagic Ellös AB (Ellös, Sweden). These wastewater streams and their origin are presented in Fig. 1, and their compositional characterization has been gathered in Table 1. Accordingly, salt brine and end-of-pipe represent streams upstream of the separation tank, while sludge and wastewater are the fractions obtained in the latter. The streams were heat sterilized at $121{ }^{\circ} \mathrm{C}$ for $20 \mathrm{~min}$ in an autoclave (Systec, Karlsruhe, Germany) and stored at $4{ }^{\circ} \mathrm{C}$ until use.

\section{Microorganism}

Aspergillus oryzae var. oryzae CBS 819.72 (Centraalbureau voor Schimmelcultures, Utrecht, The Netherlands) was used throughout the study. This edible fungus strain was maintained on PDA (Potato Dextrose Agar) plates containing $4 \mathrm{~g} / \mathrm{L}$ potato infusion, $20 \mathrm{~g} / \mathrm{L}$ glucose, and $15 \mathrm{~g} / \mathrm{L}$ agar. New plates were prepared by flooding pregrown agar plates with $20 \mathrm{~mL}$ sterile distilled water and spores were brought into solution with an L-shape disposable plastic spreader. $100 \mu \mathrm{L}$ of spore solution were then added to new agar plates, spread with another L-shape 
Fig. 1 Overall scheme of the fish processing process with originated products and wastewater streams. The streams used in this study are highlighted as well as the overall aim of the study, namely, their conversion into protein-rich fungal biomass. Modified from Sar et al. [15]

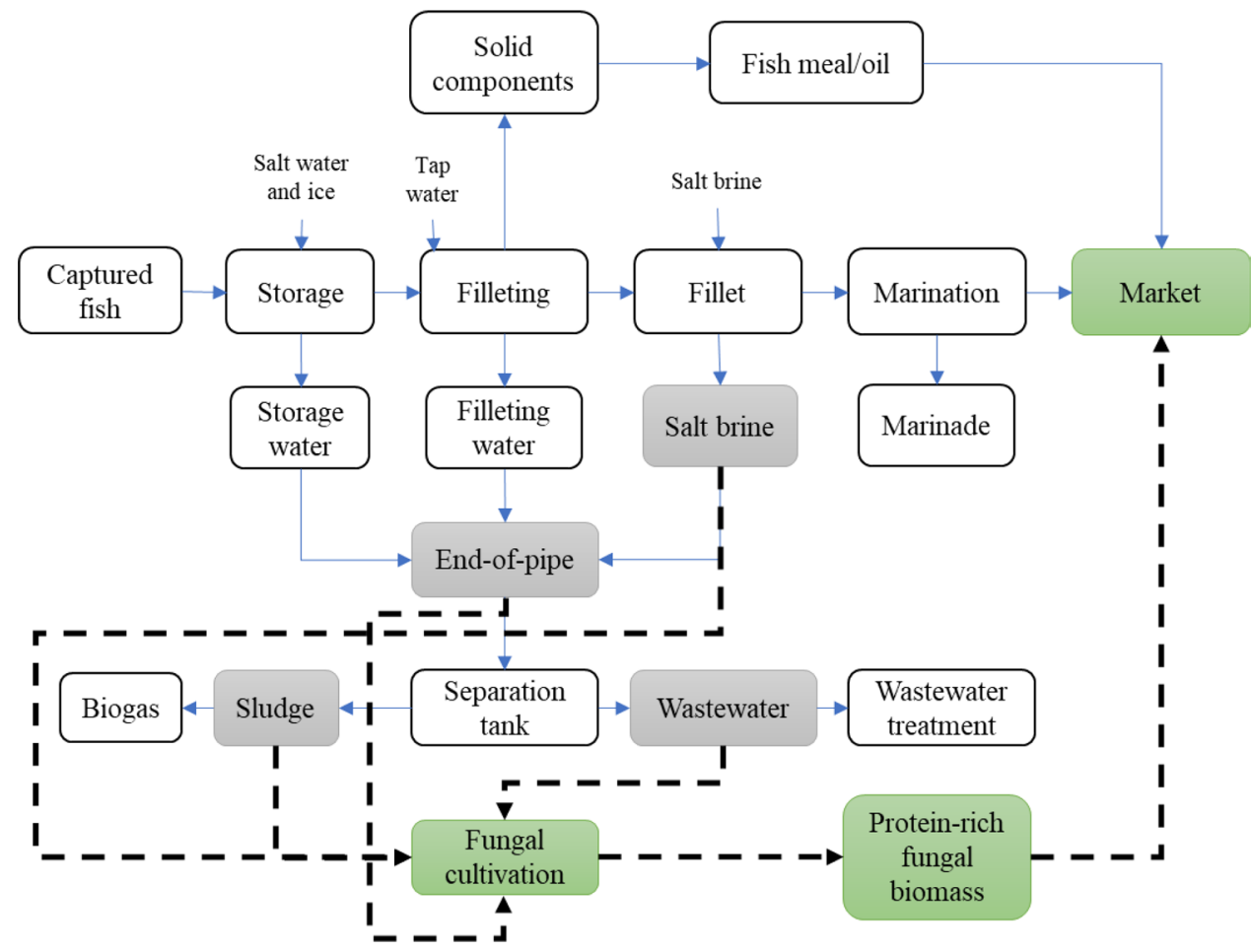

disposable plastic spreader, and incubated at $30{ }^{\circ} \mathrm{C}$ for 3 days. After incubation, the newly grown fungal plates were stored at $4{ }^{\circ} \mathrm{C}$ until use [11].

\section{Cultivation in shake-flasks}

Series of cultivations using A. oryzae were performed in $250 \mathrm{~mL}$ wide-necked Erlenmeyer flasks containing $50 \mathrm{~mL}$ of medium (salt brine, end-of-pipe, sludge, wastewater, or a mixture of sludge and wastewater). In addition to the stream type, the effect of initial $\mathrm{pH}$ (initial $\mathrm{pH}$ vs. $\mathrm{pH} 5.0$ adjusted with $2 \mathrm{M} \mathrm{H}_{2} \mathrm{SO}_{4}$ ), supplementation (trace metals or trace metals and vitamins according to Sues et al. [16]) and mixing ratio of sludge and wastewater, were also studied. Each flask was inoculated with $1 \mathrm{~mL}$ of $A$. oryzae spore solution containing $1.69 \pm 0.19 \times 10^{7}$ spores/ $\mathrm{mL}$, followed by incubation in a water bath (Grant OLSAqua pro, Cambridge, UK) at $35^{\circ} \mathrm{C}$ with orbital shaking at $125 \mathrm{rpm}$ for $24-120 \mathrm{~h}$. At the end of the cultivation, the medium was poured through a kitchen sieve $\left(1 \mathrm{~mm}^{2}\right.$ pore size); the recovered fungal biomass/solids (entangled biomass with remaining medium suspended solids) was washed with distilled water for removal of medium components before gravimetric analysis, for yield determination [15]. Yields of recovered fungal biomass/solids are reported as grams of recovered biomass/solids per liter of medium and as grams of recovered biomass/solids per gram of initial COD.

\section{Cultivation in bench-scale bubble column bioreactor}

Cultivations using salt brine were performed using $4.5 \mathrm{~L}$ glass bubble column bioreactors (Belach Bioteknik, Stockholm, Sweden), of $56 \mathrm{~cm}$ height and $11 \mathrm{~cm}$ width [15]. The bioreactors were empty sterilized at $121^{\circ} \mathrm{C}$ for $20 \mathrm{~min}$ and filled with $3 \mathrm{~L}$ of sterile salt brine. The initial $\mathrm{pH}$ was adjusted to 5.5 with $2 \mathrm{M} \mathrm{H}_{2} \mathrm{SO}_{4}$ using the bioreactor-coupled peristaltic pump. Each bioreactor was inoculated with $20 \mathrm{~mL} / \mathrm{L}$ of spore solution $\left(1.69 \pm 0.19 \times 10^{7}\right.$ spores $\left./ \mathrm{mL}\right)$ followed by cultivation at $35{ }^{\circ} \mathrm{C}$ with a continuous aeration rate of $0.5 \mathrm{vvm}$ (volume of air per volume of medium per minute). At the end of the cultivation, the biomass was recovered as aforementioned.

\section{Analytical methods}

Yields of recovered biomass/solids, in grams per liter of medium, were determined via gravimetric analysis using oven drying at $70{ }^{\circ} \mathrm{C}$ until constant weight [15].

The medium before and after fungal treatment was characterized regarding content of total solids and dissolved solids according to Sluiter et al. [17], ash according to Sluiter et al. [18], and COD using a COD kit (Nanocolor COD 1500, Düren, Germany).

Crude protein analysis of both biomass and medium samples was performed according to the Kjeldahl method [11], nitrogen-to-protein conversion factors of 6.25 [11] and 5.60 [19] were used for biomass and fish processing-derived 
Table 1 Compositional analysis of the fish processing-derived wastewater streams used in this study and highlighted in Fig. 1. Modified from Sar et al. [15]

\begin{tabular}{|c|c|c|c|c|}
\hline Component & Wastewater & Sludge & Salt brine & End-of-pipe \\
\hline $\mathrm{pH}$ & 6.90 & 6.10 & 6.33 & 6.53 \\
\hline Total COD $(\mathrm{g} / \mathrm{L})$ & $3.53 \pm 0.19$ & $104.00 \pm 4.00$ & $19.80 \pm 1.20$ & $11.00 \pm 1.20$ \\
\hline Dissolved COD $(\mathrm{g} / \mathrm{L})$ & $3.07 \pm 0.19$ & $11.00 \pm 0.01$ & $9.60 \pm 0.00$ & $4.20 \pm 0.00$ \\
\hline Total solids (g/kg) & $16.93 \pm 0.21$ & $104.75 \pm 2.50$ & $41.80 \pm 0.58$ & $9.91 \pm 0.13$ \\
\hline Dissolved solids (g/kg) & $12.09 \pm 4.10$ & $11.84 \pm 0.02$ & $26.16 \pm 1.17$ & $5.65 \pm 1.10$ \\
\hline Volatile solids (g/kg) & $2.62 \pm 0.31$ & $89.17 \pm 2.30$ & $15.92 \pm 0.00$ & $4.93 \pm 0.06$ \\
\hline Ash $(g / k g)$ & $14.46 \pm 0.61$ & $15.58 \pm 0.21$ & $25.87 \pm 0.58$ & $4.98 \pm 0.07$ \\
\hline Nitrogen $(\mathrm{g} / \mathrm{kg})$ & $0.51 \pm 0.03$ & $8.43 \pm 2.06$ & $2.64 \pm 0.06$ & $0.60 \pm 0.03$ \\
\hline Crude protein $(\mathrm{g} / \mathrm{kg})$ & $2.83 \pm 0.17$ & $47.21 \pm 11.54$ & $14.79 \pm 0.14$ & $3.36 \pm 0.14$ \\
\hline Crude fat $(\mathrm{g} / \mathrm{kg})$ & $6.42 \pm 0.73$ & $43.27 \pm 4.95$ & $29.42 \pm 1.48$ & $7.52 \pm 0.73$ \\
\hline Glucose (g/L) & $0.017 \pm 0.004$ & $0.009 \pm 0.005$ & $0.013 \pm 0.01$ & $0.031 \pm 0.00$ \\
\hline Other sugars $(\mathrm{g} / \mathrm{L})$ & $0.013 \pm 0.001$ & $0.014 \pm 0.001$ & $0.017 \pm 0.01$ & $0.026 \pm 0.00$ \\
\hline Glycerol (g/L) & $0.003 \pm 0.001$ & $0.016 \pm 0.002$ & $0.027 \pm 0.01$ & $0.208 \pm 0.03$ \\
\hline Lactic acid (g/L) & $0.388 \pm 0.081$ & $0.385 \pm 0.013$ & $0.017 \pm 0.01$ & $0.023 \pm 0.00$ \\
\hline Acetic acid $(\mathrm{g} / \mathrm{L})$ & $0.203 \pm 0.064$ & $0.680 \pm 0.008$ & $0.007 \pm 0.01$ & $0.012 \pm 0.00$ \\
\hline Ethanol (g/L) & $0.012 \pm 0.005$ & $0.059 \pm 0.039$ & $0.000 \pm 0.00$ & $0.010 \pm 0.01$ \\
\hline Cadmium (ppm) & $10.10 \pm 6.25$ & nd & $12.77 \pm 8.49$ & $13.21 \pm 7.12$ \\
\hline Calcium (ppm) & $20.34 \pm 3.41$ & $72.92 \pm 3.38$ & $20.24 \pm 4.95$ & $19.45 \pm 1.69$ \\
\hline Copper (ppm) & $0.32 \pm 0.07$ & $0.27 \pm 0.07$ & $0.33 \pm 0.18$ & $0.12 \pm 0.02$ \\
\hline Nickel (ppm) & $0.05 \pm 0.01$ & $0.05 \pm 0.02$ & $0.07 \pm 0.03$ & $0.02 \pm 0.01$ \\
\hline Cobalt (ppm) & $1.08 \pm 0.52$ & $1.33 \pm 0.73$ & $1.24 \pm 0.77$ & $0.98 \pm 0.45$ \\
\hline Lead (ppm) & $0.41 \pm 0.15$ & $0.54 \pm 0.18$ & $0.49 \pm 0.29$ & $0.22 \pm 0.07$ \\
\hline Magnesium (ppm) & $47.32 \pm 2.94$ & $71.8 \pm 5.62$ & $86.85 \pm 16.48$ & $26.85 \pm 0.78$ \\
\hline Iron (ppm) & $0.52 \pm 0.11$ & $2.63 \pm 0.31$ & $0.52 \pm 0.20$ & $0.59 \pm 0.09$ \\
\hline Potassium (ppm) & $492.33 \pm 151.33$ & $723.02 \pm 273.25$ & nd & $356.99 \pm 144.19$ \\
\hline Chromium (ppm) & $0.02 \pm 0.01$ & $0.06 \pm 0.01$ & $0.02 \pm 0.02$ & $0.02 \pm 0.01$ \\
\hline Aluminum (ppm) & $3.26 \pm 0.37$ & $759.55 \pm 63.94$ & $0.19 \pm 0.13$ & $0.21 \pm 0.10$ \\
\hline
\end{tabular}

$n d$ not detected streams, respectively. Total fat content of the streams was determined by extraction with organic solvent according to Majdejabbari et al. [20] with modification. The substrates were diluted with ultrapure water and then vigorously mixed with an organic solvent ( $30 \mathrm{~mL}$ ethanol: $75 \mathrm{~mL}$ diethyl ether: $75 \mathrm{~mL}$ petroleum ether). The organic layer was separated and evaporated under a fume hood. The amount of fat was determined by weight of the evaporated organic materials.

Concentrations of glucose, sugars other than glucose, lactic acid, acetic acid, and ethanol were determined by high-performance liquid chromatography (HPLC) (Waters 2695, Waters Corporation, Milford, MA, USA) equipped with a analytical ion exchange column based on hydrogen ions (Aminex HPX-87H, BioRad, Hercules, CA, USA). The HPLC analysis was operated at $60{ }^{\circ} \mathrm{C}$ with $0.6 \mathrm{~mL} / \mathrm{min}$ of $5 \mathrm{mM} \mathrm{H}_{2} \mathrm{SO}_{4}$ as eluent and the detection was carried out by a refractive index (RI) detector (Waters 2414, Waters Corporation, Milford, MA, USA) [11].

Minerals including cadmium, calcium, copper, nickel, cobalt, lead, magnesium, iron, potassium, chromium, and aluminum, were determined through Microwave
Plasma-Atomic Emission Spectroscopy (MP-AES 4200, Agilent Technologies, Santa Clara, CA, USA) [15].

\section{Statistical analysis}

All experiments were carried out in duplicate and the obtained results were statistically analyzed using Minitab $17^{\circledR}$. Analysis of variance (ANOVA) using general linear models was carried out, and significant differences were considered at $p$ value $<0.05$ within a $95 \%$ confidence interval. Pairwise comparisons among groups of data were also carried out according to the Tukey's test. All error bars and intervals represent 2 times the standard deviation.

\section{Results and discussion}

\section{Herring fillet: process and wastewater streams}

After capture, herring can be stored in salt water and ice before entering the filleting process, giving rise to storage 
wastewater (Fig. 1). During filleting, fish solid components such as heads, tails, backbones, and trimmings are separated and normally used for production of fish meal/oil [21], and the fillet is washed with tap water giving rise to filleting wastewater. Before marination, the fillet is treated with salt brine (3-13\% for $6-24 \mathrm{~h}$ ), giving rise to salt brine wastewater. After marination, the fillet is ready for the market leaving marinade as wastewater. All originated wastewater streams are mixed giving rise to "end-of-pipe", if all processing steps take place in the same facility. For instance, in the process reported in this study, marinade is not originated and it does not join the end-of-pipe stream collected for this study. The end-of-pipe stream goes to the separation tank, where addition of polyaluminum chloride and $\mathrm{pH}$ adjustment take place to induce solid aggregation [22]. Phase separation originates sludge, corresponding to the solid phase and generally directed to biogas production, and wastewater, corresponding to the liquid phase and normally directed to wastewater treatment (Fig. 1).

As a consequence of salt water addition and the treatment taking place in the separation tank, a high amount of minerals was found in the wastewater streams in addition to fish-derived proteins and fat (Table 1). Therefore, considering their composition, the wastewater streams have the potential to support filamentous fungal growth and originate protein-rich biomass that can be used as a replacement for fish meal in aquaculture [6].

The wastewater streams used in this study had dissimilar composition regarding the amount of minerals and of suspended solids. For instance, the ratio of total solids to dissolved solids, which points out the amount of suspended solids, was found to be considerably higher in sludge in comparison to the other wastewater streams (Table 1). Therefore, a growth screening will reveal the effect of the stream origin on growth of an edible filamentous fungus regarding growth rate, biomass production yield, and biomass composition. Consequently, it will shed light onto the most promising integration strategies leading to wastewater valorization with potential positive economic and environmental impacts on overall fish processing process.

\section{Cultivation in sludge and wastewater}

The filamentous fungal biomass obtained after cultivation in sludge was visibly entangled with medium suspended solids into an easily recovered macroscopic structure by sieving. Therefore, the term "recovered solids" instead of "fungal biomass" was used to characterize the growth performance of A. oryzae (Fig. 2). Entanglement of fungal filaments with suspended solids and its impact on the final
Fig. 2 Effect of the sludge fraction mixed with wastewater $(\mathbf{a}, \mathbf{b})$, sludge supplementation, and initial $\mathrm{pH}(\mathbf{c})$, and extent of washing (d), on the amount of harvested solids (a, $\mathbf{c}, \mathbf{d})$, and on the yield of harvested solids per gram of total COD (b)
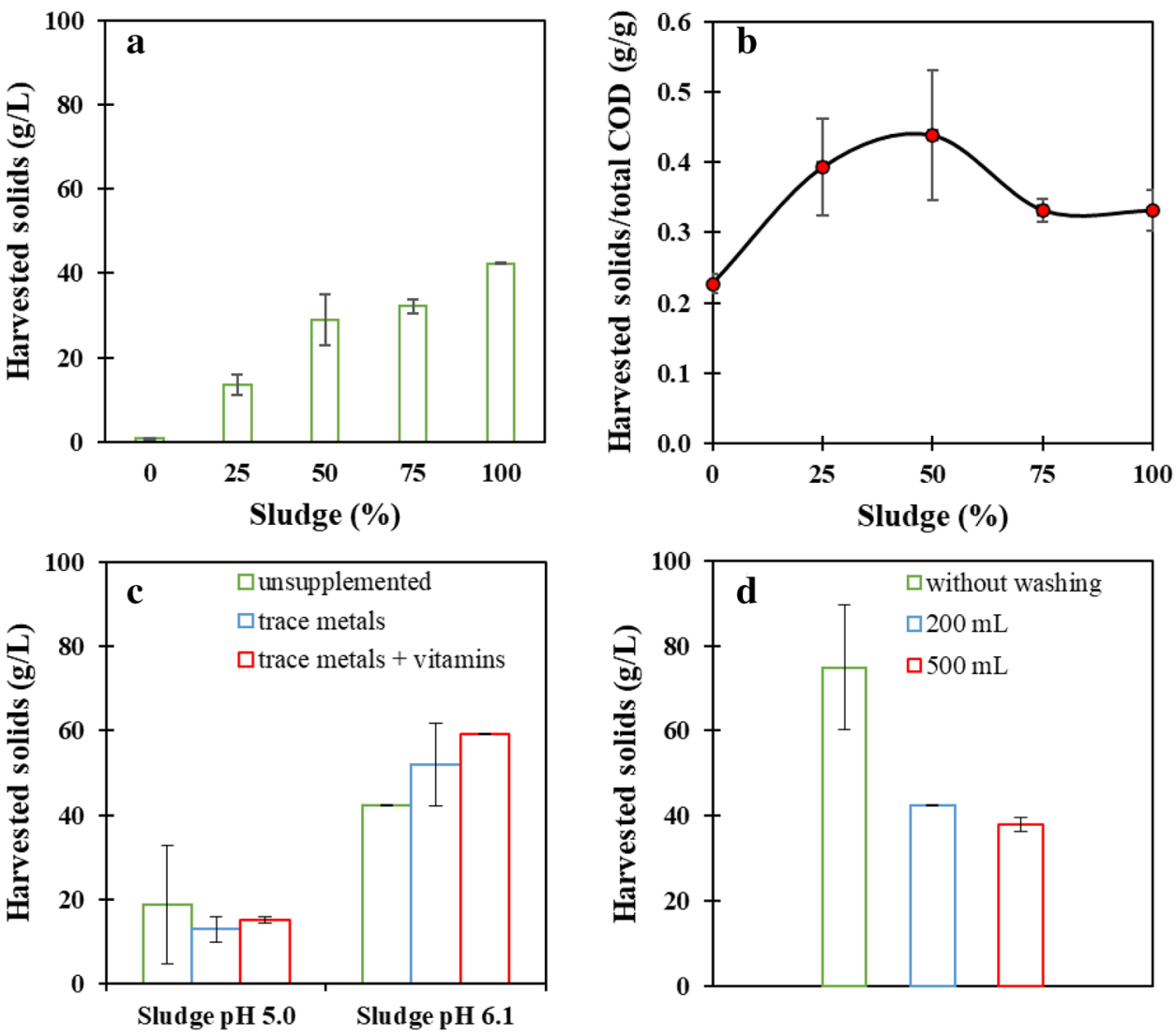
concentration of recovered product has also been reported by Rasmussen et al. [8] and Souza Filho et al. [23].

In the first approach, the effect of sludge percentage mixed with wastewater was investigated during cultivation for $72 \mathrm{~h}$ at the stream original $\mathrm{pH}$ (Table 1). As it is presented in Fig. 2a, $<1 \mathrm{~g} / \mathrm{L}$ solids were recovered when only wastewater was used, in agreement with the low concentration of nutrients available in this stream (Table 1). An increase in the sludge fraction mixed with wastewater was found to not influence negatively the amounts of recovered solids following A. oryzae cultivation (Fig. 2a), and the yield of recovered solids per gram of initial COD (Fig. 2b). The sludge fraction used during cultivation was found to have an effect ( $p$ value $<0.001$ ) on the amounts of recovered solids, where the cultivation in 100\% sludge led to the highest amount. Altogether, when only sludge was used as cultivation medium, ca. $42 \mathrm{~g} / \mathrm{L}$ of solids were recovered corresponding to a yield of $0.33 \mathrm{~g}$ of solids per gram of total initial COD. In a previous study, the fraction of sludge was found to play a role on the amount of recovered solids after cultivation of the zygomycete fungus $R$. oryzae, where a sludge fraction above $50 \%$ had a detrimental effect on fungal growth [15]. Therefore, A. oryzae seems to be a more robust filamentous fungus in the conditions studied, likely towards the amount of suspended solids, nutrient balance, and concentration of potential inhibitors. For instance, an aluminum concentration of 500-1000 ppm has been reported to lead to growth failure of Aspergillus spp. [24]. The fact that A. oryzae could grow in $100 \%$ sludge-containing $759.55 \pm 63.94 \mathrm{ppm}$ of aluminum, corroborates the thesis that the inhibitory effect by e.g. minerals can be influenced by medium recipe, cultivation conditions, and fungal strain [25]. For instance, different dilution strategies of ethanol side-streams, namely, rum-(127 g/L COD), molasses-(79 g/L COD), and cane(COD) derived vinasse, were needed in order to achieve optimal growth of Rhizopus microsporus (var. oligosporus). In another study, concentrated vinasse needed to be diluted to a final concentration of 5\% (21 g/L COD) to achieve optimal growth of A. oryzae, Neurospora intermedia, and $R$. oryzae [10].

In addition to the medium recipe, parameters such as $\mathrm{pH}$ can influence the growth performance of the filamentous fungus. Therefore, the effect of supplementation and initial $\mathrm{pH}$ on growth of A. oryzae in $100 \%$ sludge was also studied (Fig. 2c). A clear effect of the initial $\mathrm{pH}$ on the amounts of recovered solids was observed when adjusting the initial $\mathrm{pH}$ of 6.1-5.0; a reduction of more than 50\% on the amount of recovered solids was obtained. Such difference was corroborated by statistical analysis ( $p$ value $<0.001$ ), that also demonstrated that medium supplementation, and factor interaction, namely, of $\mathrm{pH}$ and medium supplementation, did not have an effect on the amount of recovered solids.
Due to visible entanglement of $A$. oryzae filaments with sludge-containing solids, the effect of extent of washing on the amounts of recovered solids was also studied (Fig. 2d). During sieving, the recovered solids were only pressed, washed with $200 \mathrm{~mL}$ of distilled water (the reference method) and with $500 \mathrm{~mL}$ of distilled water. Washing the solids with $200 \mathrm{~mL}$ distilled water had a significant effect on the recovery amount ( $p$ value $=0.16$ ) leading to a reduction of $43 \%$ in comparison to that when only pressing was applied. A further increase in the amount of distilled water used for washing did not influence the final recovery solids (from ca. 42 to $38 \mathrm{~g} / \mathrm{L}$ ) (Fig. 2d).

Lastly, the effect of cultivation time on the amount of recovered solids and $\mathrm{pH}$ was studied (Fig. 3). A cultivation time of $72 \mathrm{~h}$, at which all aforementioned results were obtained, was found to lead to the highest value of recovered solids; a shorter or longer cultivation time by $24-48 \mathrm{~h}$ led to significantly lower amounts of recovered solids $(p$ value $<0.001$ ). The medium $\mathrm{pH}$ was found to remain rather constant after $48 \mathrm{~h}$ of cultivation; an increase in $\mathrm{pH}$ from 6.1 to 6.7 was observed after $72 \mathrm{~h}$ of cultivation (Fig. 3).

The obtained results from the study on the effect of initial $\mathrm{pH}$, medium supplementation, and cultivation time are in agreement with previous results obtained from the cultivation of $R$. oryzae in $50 \%$ fish processing-originated sludge [15], a cultivation time of $72 \mathrm{~h}$ was also needed to obtain the highest amount of harvested solids.

\section{Cultivation in salt brine and end-of-pipe}

As presented in Table 1, and discussed in previous sections, the ratio between total solids and dissolved solids in salt brine and end-of-pipe is lower in comparison to that of sludge. Therefore, the extent of entanglement of fungal filaments with suspended solids should be lower, producing a "purer" filamentous fungal biomass, and hence worth studying.

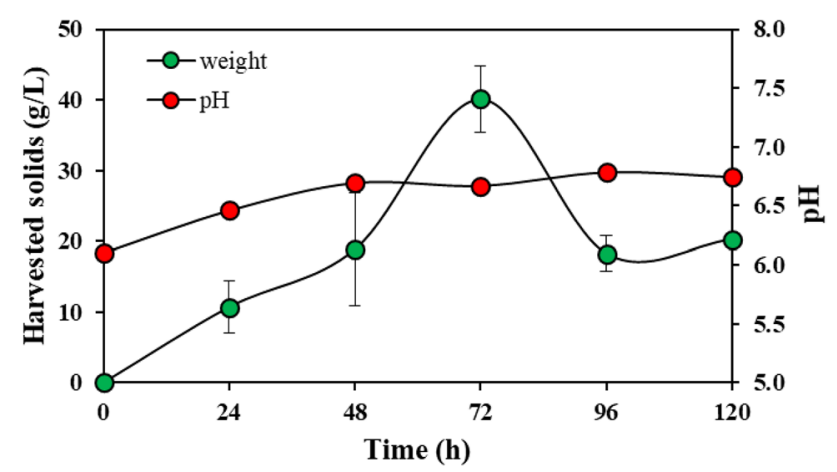

Fig. 3 Profile of the yield of recovered solids and $\mathrm{pH}$ during cultivation of A. oryzae in $100 \%$ sludge 
Cultivation of $A$. oryzae in salt brine was found to be very sensitive to the cultivation time in comparison to that in end-of-pipe (Fig. 4a, b). The highest amount of biomass was obtained after $48 \mathrm{~h}$ of cultivation in both streams. However, a higher amount of biomass of $4.1 \mathrm{~g} / \mathrm{L}$ was obtained after cultivation in salt brine in comparison to that obtained after cultivation in end-of-pipe $(1.9 \mathrm{~g} / \mathrm{L})$. Similarly to the cultivations carried out in sludge, medium supplementation did not have a significant positive impact on the production of fungal biomass (Fig. 4a, b). Altogether, yields of 0.21 and $0.17 \mathrm{~g}$ of biomass per gram of initial COD were obtained after cultivation of $A$. oryzae in salt brine and in end-of-pipe, respectively, which are lower than that obtained during cultivation in $100 \%$ sludge, namely, of $0.33 \mathrm{~g} / \mathrm{g}$. The higher yield obtained by $A$. oryzae cultivation in sludge might be a result of higher biomass entanglement with suspended solids or due to dissimilar nutrient balance. For instance, Nitayavardhana, Khanal [7] reported the need of nutrient balancing, namely, the ratio of soluble COD:N:P, for optimal growth of $R$. microsporus (var. oligosporus) in ethanol production side-streams. The yields obtained in this study are similar to those available in the literature. For instance, Hultberg, Bodin [26] have reported a yield of $0.32 \mathrm{~g}$ of biomass per gram of COD following cultivation of Pleurotus ostreatus for 3 days in synthetic brewery wastewater; Hultberg, Bodin [27] reported a yield of $0.26 \mathrm{~g}$ of biomass per gram of COD following cultivation of $P$. ostreatus for 10 days in brewery waste streams; and Souza Filho et al. [23] have reported a yield range of $0.21-0.39 \mathrm{~g}$ of biomass per gram of COD following growth of $R$. oryzae and $A$. oryzae for 3 days in starch plant wastewater.

The fungal biomass obtained during cultivation in salt brine and end-of-pipe was visibly less influenced by entanglement with suspended solids than the recovered material after cultivation in sludge. Therefore, a further cultivation in salt brine, from which a higher biomass amount was obtained in comparison to that in end-of-pipe, was carried out in a bubble column bioreactor (Fig. 4c). The amounts of fungal biomass obtained in both shake-flasks and bubble column bioreactor were not statistically different ( $p$ value $0.091)$. Cultivation in bubble column bioreactors leads normally to higher yields of biomass, in comparison to those obtained using shake-flasks, due to the continuous supply of air that increases oxygen availability to the cells. Aeration rate has been used to steer the share of biomass and ethanol produced by the ascomycete $N$. intermedia during cultivation in ethanol side-streams [28].

Similar biomass yields, in grams of biomass per gram of initial COD, were obtained in a previous work, where $R$. oryzae was cultivated in salt brine and end-of-pipe [15]. A similar cultivation time was needed to achieve the highest amount of fungal biomass in salt brine, whereas the highest
Fig. 4 Fungal biomass concentration profiles obtained from cultivation of $A$. oryzae in salt brine (a) and end-of-pipe (b). A comparison between fungal biomass produced from cultivation in salt brine using shake-flasks and a $4.5 \mathrm{~L}$ bubble column bioreactor is also presented $(\mathbf{c})$
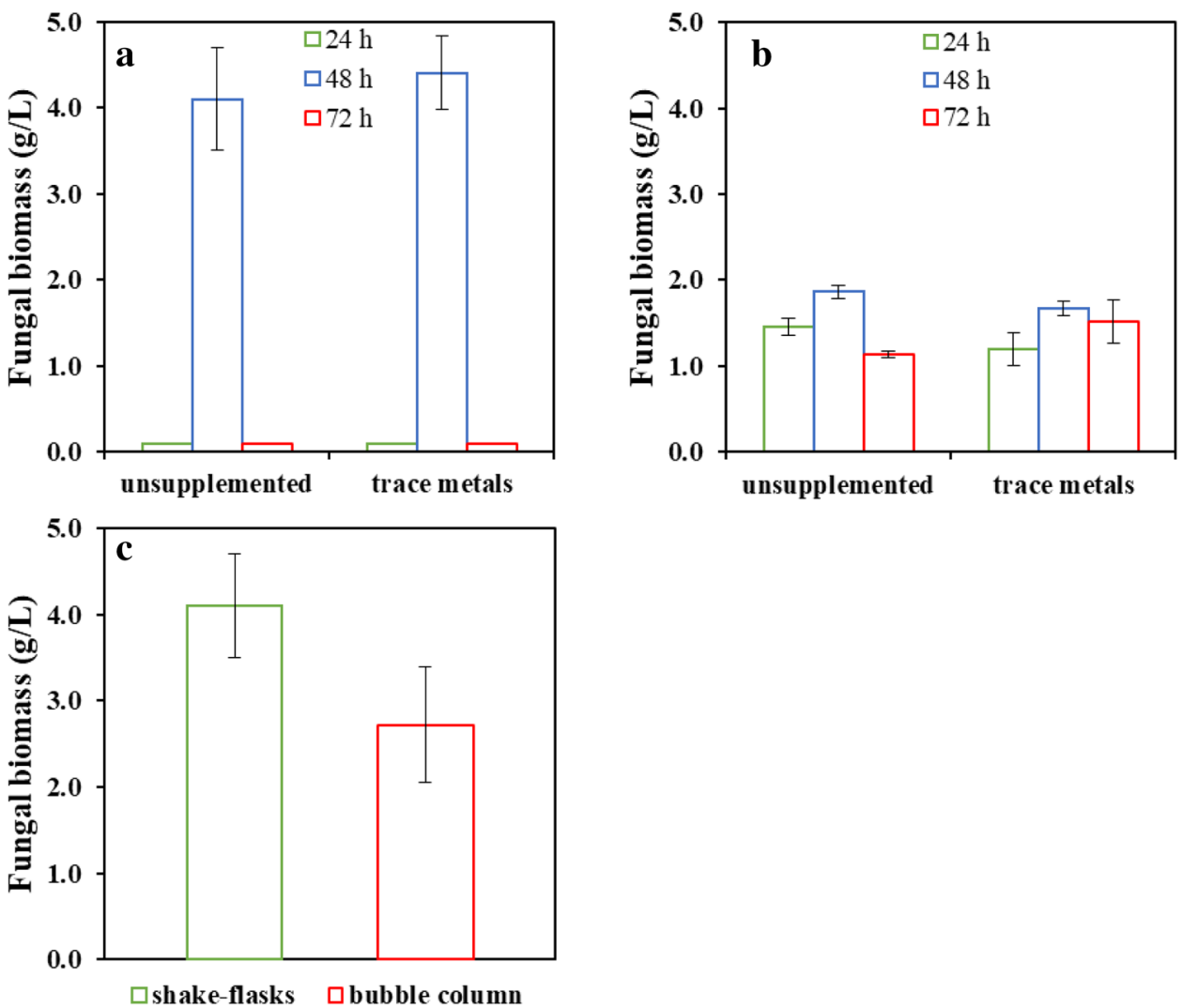
amount of $R$. oryzae biomass was obtained already after $24 \mathrm{~h}$ of cultivation under similar conditions.

\section{Characterization of fungal biomass}

In addition to the effect of stream origin, cultivation time, medium supplementation, washing extent, and experimental scale, on the amount of recovered solids/fungal biomass from the medium, their effect on the biomass crude protein content was investigated (Fig. 5).

The cultivation time and the extent of washing during material harvesting were found to play a significant role in the protein content of the recovered solids/fungal biomass (Fig. 5b, c), contrary to medium supplementation and cultivation scale (Fig. 5a, b). The effect of cultivation time was observed after $48 \mathrm{~h}$ of cultivation, where the recovered solids were composed of ca. $30 \%$ protein, in comparison to those after $24 \mathrm{~h}$ of cultivation, which were composed of $42 \%$ protein (Fig. 5b). An effect on the protein content of the biomass was found when $500 \mathrm{~mL}$ of distilled water were used instead of pressing or addition of $200 \mathrm{~mL}$ of distilled water, where a reduction from 34 to $27 \%$ was found. Therefore, there is the potential of increasing the amount of harvested material from 42 to $75 \mathrm{~g} / \mathrm{L}$ without compromising the final protein content. Overall, the results obtained point out that lack of accessible nitrogen in the medium, metabolic shifts leading to the production of other cell mass components, or the presence of high amount of suspended solids, might have influenced the composition of the final product. Further investigations are needed on the effect of cultivation time, nitrogen supplementation, and presence of suspended solids on the overall composition of the recovered solids including protein, fat, and cell wall components, especially chitin.

Aspergillus oryzae biomass obtained after cultivation in salt brine was found to contain a comparatively higher protein content, of 58-62\%, which was similar at both cultivation scales investigated (Fig. 5d). Altogether, the protein contents of the material recovered after cultivation in sludge were lower as compared to those reported in the literature, where fungal biomass was produced from ethanol sidestreams using various strains of filamentous fungi, yielding protein from 42 to $58 \%[7,8,10,11,28]$. A study carried out by Souza Filho et al. [23] has hypothesized that the amount of suspended solids influenced the protein content of A. ory$z a e$ and $R$. oryzae biomass, where a decrease from $35 \%$ to less than $17 \%$ protein was found when potato starch waste stream higher in suspended solids was used for cultivation. A similar situation might have taken place in the current study in view of the dissimilar concentration of suspended solids among sludge and salt brine. Nonetheless, as aforementioned, further studies are need to clarify this outcome.

\section{Characterization of cultivation-derived streams}

In addition to the value-added products, such as a proteinrich product for feed applications, the use of filamentous
Fig. 5 Effect of medium supplementation (a), cultivation time (b) and washing (c) on the crude protein content of $A$. ory$z a e$ biomass cultivated in $100 \%$ sludge. A comparison on crude protein with $A$. oryzae biomass cultivated in salt brine using shake-flasks and bubble column bioreactors is also presented (d)
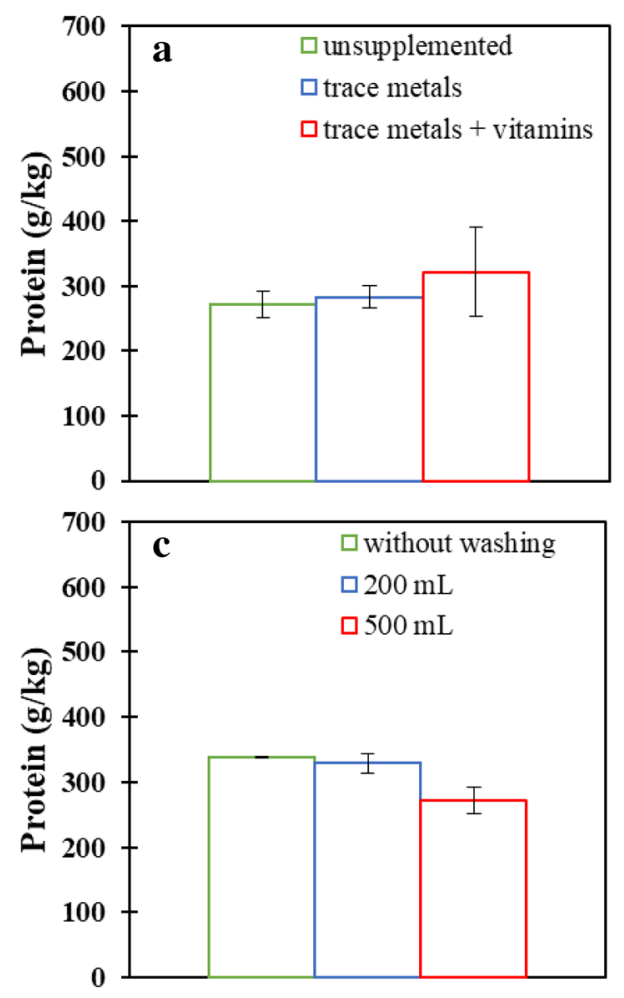
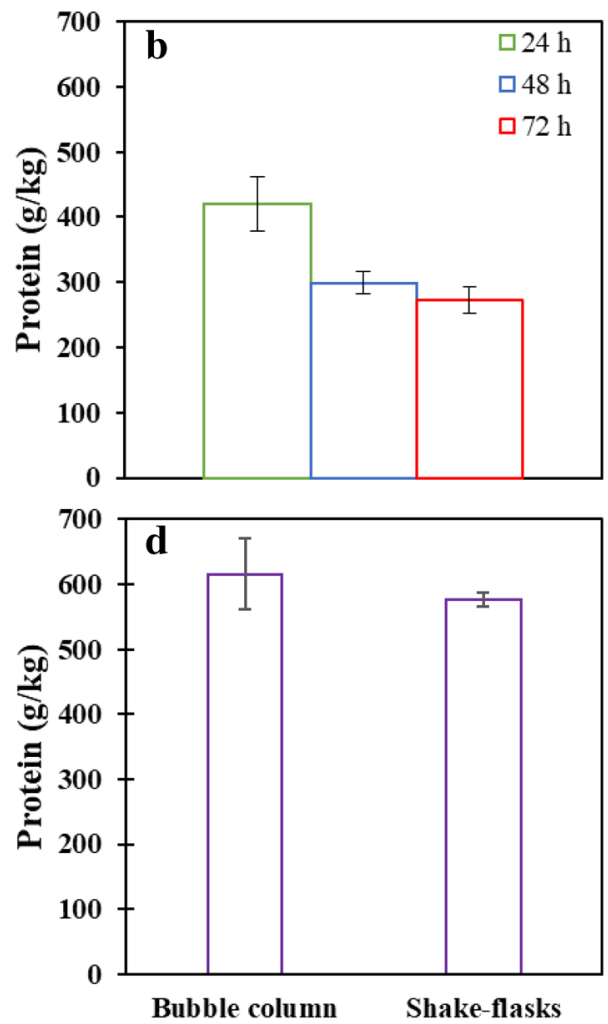
fungi for valorization of industrial side-streams can also have an impact on water reclamation due to reduced load of organic matter, following solids/fungal biomass separation by sieving. Accordingly, the streams originated after fungal growth and harvesting, were characterized regarding COD, total solids, and nitrogen (Fig. 6).

After $72 \mathrm{~h}$ of cultivation of A. oryzae in sludge and sieving, COD, total solids, and nitrogen had been reduced by ca. $12-35 \%, 39-55 \%$, and $55-66 \%$, respectively, while applying different supplementation strategies (Fig. 6a). Reasonably, medium supplementation did not have a significant influence on these parameters ( $p$ values $>0.05$ ), similarly to the results obtained for the amounts of sieved solids. After cultivation of the ascomycete in salt brine using shake-flasks and bubble column bioreactor, COD, total solids, and nitrogen removal ranges of $33-43 \%, 91-92 \%$, and $32-39 \%$, respectively, were obtained. Statistical differences were only found on the removal of nitrogen ( $p$ value 0.028 ), where cultivation in bubble column bioreactor led to the highest removal. The fact the nitrogen was not totally removed gives further weight to the hypothesis of lack of accessible nitrogen, leading to a decrease in the protein content of fungal biomass during progression of the cultivation.

COD, total solids, and nitrogen removal ranges following cultivation of $R$. oryzae in $50 \%$ sludge with wastewater were $34-58 \%, 61-77 \%$, and $62-72 \%$, respectively [15]. These results corroborate, therefore, the superior growth robustness of A. oryzae in sludge-containing medium. Aspergillus oryzae has also been reported to exhibit a superior growth performance than that of $R$. oryzae in potato plant wastewater [23]. COD, total solids, and nitrogen removal ranges of $56-69 \%, 92-93 \%$, and 35-39\%, respectively, were obtained during $R$. oryzae cultivation in end-of-pipe, using shakeflasks and bubble column bioreactors [15]. Therefore, similar total solids and nitrogen removal ranges, and somewhat lower COD removal ranges, were obtained after cultivation of $A$. oryzae in salt brine, which has comparatively higher COD (19.8 vs. $11 \mathrm{~g} / \mathrm{L}$ ), total solids (ca. 42 vs. ca. $10 \mathrm{~g} / \mathrm{L}$ ), and nitrogen ( 2.6 vs. $0.6 \mathrm{~g} / \mathrm{L}$ ). Other research works applying filamentous fungi for valorization of ethanol side-streams have reported reductions of $42 \%$ in soluble COD (initially of $69 \mathrm{~g} / \mathrm{L}$ ) using Rhizopus microsporus (var. oligosporus) [7] and 33-46\% (initial COD of $21 \mathrm{~g} / \mathrm{L}$ ) using A. oryzae, $N$. intermedia, and $R$. oryzae [10], and up to $85 \%$ (initial COD of $27-37 \mathrm{~g} / \mathrm{L}$ ) following growth of $A$. oryzae and $R$. oryzae in potato plant wastewater [23]. Overall, the aim of reducing the COD of fish industry's wastewaters, for easier further treatment, was fulfilled. However, it is hypothesized that developing a process centered on carbon and nitrogen balance, medium dilution, and combination of biological and chemical processes, can lead to effluents that can respect discharge limits and offset the need of further wastewater treatment. However, these strategies need to be parallelly supported by techno-economic analyses and life-cycle assessments.

\section{Conclusion}

The results of this study point out that fish processing wastewaters provide versatility to the development of biological processes leading to their conversion into protein-rich fungal biomass, for feed applications, and effluents with comparatively lower COD levels. Aspergillus oryzae was found to grow in all wastewaters studied in this work; however, further studies are needed on the impact of medium supplementation and dilution, and combination of biological and e.g. chemical strategies, on the remaining COD levels and consequent need of further wastewater treatment. This together with the dissimilar output regarding concentration
Fig. 6 Removal ratios of total COD, total solids, and nitrogen after cultivation of $A$. oryzae in $100 \%$ sludge with varying medium supplementation using shake-flasks (a), and in salt brine at both shake-flasks and bubble column bioreactor scales (b)
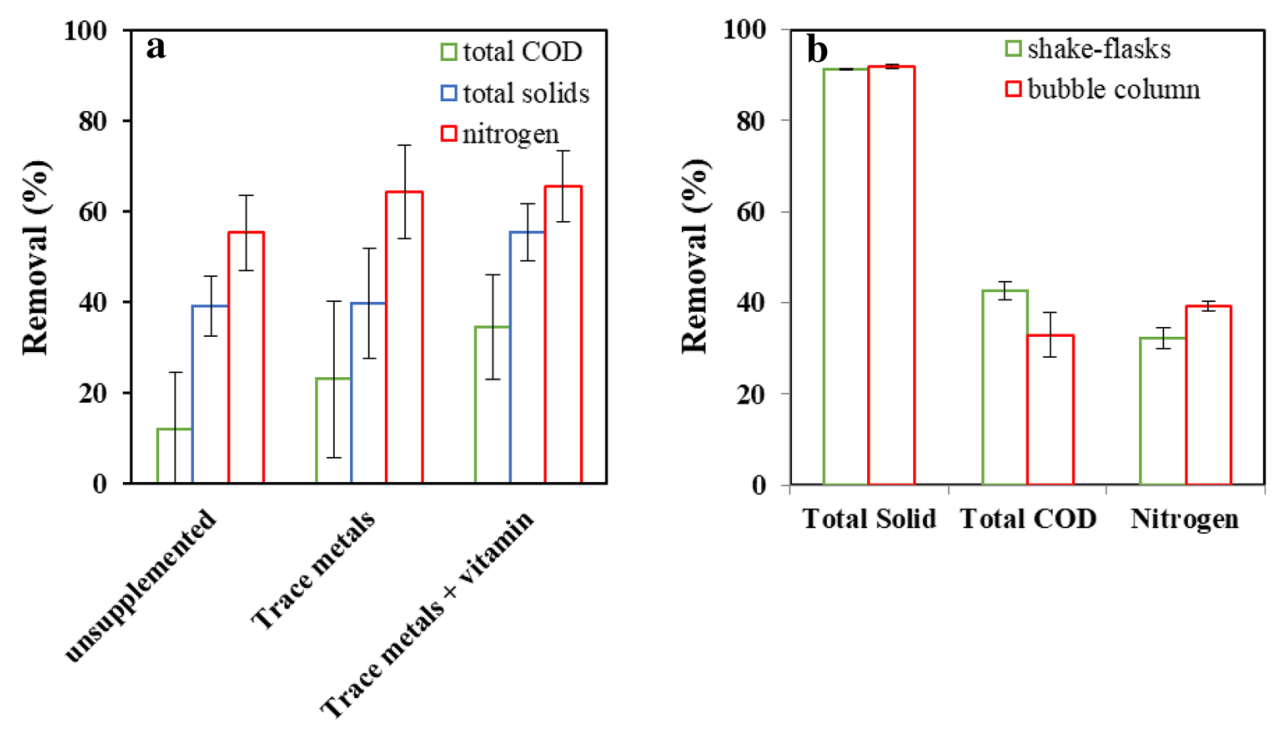
of recovery material and protein concentration, point out the need of economic, environmental, and feeding studies to reveal the most promising valorization route.

Acknowledgements Open access funding provided by University of Boras. This work was supported by the Swedish Agency for Economic and Regional Growth (Tillväxtverket) through a European Regional Development Fund. We would like to thank Scandic Pelagic Ellös AB (Ellös, Sweden) for providing the wastewater streams.

Funding This work was supported by the Swedish Agency for Economic and Regional Growth (Tillväxtverket) through a European Regional Development Fund.

\section{Compliance with ethical standards}

Conflict of interest The authors do not have any conflict of interest to declare.

Consent for publication All authors have agreed to submit the manuscript to SMAB for eventual publication.

Open Access This article is licensed under a Creative Commons Attribution 4.0 International License, which permits use, sharing, adaptation, distribution and reproduction in any medium or format, as long as you give appropriate credit to the original author(s) and the source, provide a link to the Creative Commons licence, and indicate if changes were made. The images or other third party material in this article are included in the article's Creative Commons licence, unless indicated otherwise in a credit line to the material. If material is not included in the article's Creative Commons licence and your intended use is not permitted by statutory regulation or exceeds the permitted use, you will need to obtain permission directly from the copyright holder. To view a copy of this licence, visit http://creativecommons.org/licenses/by/4.0/.

\section{References}

1. Pandey A, Höfer R, Larroche C, Taherzadeh MJ, Nampoothiri M. Industrial biorefineries and white biotechnology. Waltham: Elsevier; 2015.

2. Souza Filho PF, Andersson D, Ferreira JA, Taherzadeh MJ. Mycoprotein: environmental impact and health aspects. World J Microbiol Biotechnol. 2019;35:147.

3. Ferreira JA, Lennartsson PR, Edebo L, Taherzadeh MJ. Zygomycetes-based biorefinery: present status and future prospects. Bioresour Technol. 2013;135:523-32.

4. Ferreira JA, Mahboubi A, Lennartsson PR, Taherzadeh MJ. Waste biorefineries using filamentous ascomycetes fungi: present status and future prospects. Bioresour Technol. 2016;215:334-45.

5. FAO. How to feed the world in 2050. Accessed in 2020 .

6. Karimi S, Mahboobi Soofiani N, Mahboubi A, Taherzadeh MJ. Use of organic wastes and industrial by-products to produce filamentous fungi with potential as aqua-feed ingredients. Sustainability. 2018;10:3296.

7. Nitayavardhana S, Khanal SK. Innovative biorefinery concept for sugar-based ethanol industries: production of protein-rich fungal biomass on vinasse as an aquaculture feed ingredient. Bioresour Technol. 2010;101:9078-85.

8. Rasmussen ML, Khanal SK, Pometto AL, van Leeuwen J. Water reclamation and value-added animal feed from corn-ethanol stillage by fungal processing. Bioresour Technol. 2014;151:284-90.
9. Nair RB, Kabir MM, Lennartsson PR, Taherzadeh MJ, Horváth IS. Integrated process for ethanol, biogas, and edible filamentous fungi-based animal feed production from dilute phosphoric acid-pretreated wheat straw. Appl Biochem Biotechnol. 2018;184:48-62.

10. Karimi S, Mahboobi Soofiani N, Lundh T, Mahboubi A, Kiessling A, Taherzadeh MJ. Evaluation of filamentous fungal biomass cultivated on vinasse as an alternative nutrient source of fish feed: protein, lipid, and mineral composition. Fermentation. 2019;5:99.

11. Ferreira JA, Lennartsson PR, Taherzadeh MJ. Production of ethanol and biomass from thin stillage using food-grade Zygomycetes and Ascomycetes filamentous fungi. Energies. 2014;7:3872-85.

12. Bátori V, Åkesson D, Zamani A, Taherzadeh MJ, Sárvári HI. Anaerobic degradation of bioplastics: a review. Waste Manag. 2018:80:406-13.

13. Kafle GK, Kim SH, Sung KI. Ensiling of fish industry waste for biogas production: a lab scale evaluation of biochemical methane potential (BMP) and kinetics. Bioresour Technol. 2013;127:326-36.

14. Regueiro L, Carballa M, Álvarez JA, Lema JM. Enhanced methane production from pig manure anaerobic digestion using fish and biodiesel wastes as co-substrates. Bioresour Technol. 2012;123:507-13.

15. Sar T, Ferreira JA, Taherzadeh MJ. Bioprocessing strategies to increase the protein fraction of Rhizopus oryzae biomass using fish industry sidestreams. Waste Manag. 2020;113:261-9.

16. Sues A, Millati R, Edebo L, Taherzadeh MJ. Ethanol production from hexoses, pentoses, and dilute-acid hydrolyzate by Mucor indicus. FEMS Yeast Res. 2005;5:669-76.

17. Sluiter A, Hames B, Hyman D, Payne C, Ruiz R, Scarlata C et al. Determination of total solids in biomass and total dissolved solids in liquid process samples. National Renewable Energy Laboratory, Golden, CO, USA. NREL Technical Report No.: NREL/TP-51042621. 2008.

18. Sluiter A, Hames B, Ruiz R, Scarlata C, Sluiter J, Templeton D. Determination of ash in biomass. National Energy Laboratory, Golden, CO, USA. NREL Technical Report No.: NREL/TP-51042622. 2008.

19. Mæhre HK, Dalheim L, Edvinsen GK, Elvevoll EO, Jensen I-J. Protein determination-method matters. Foods. 2018;7:5.

20. Majdejabbari S, Barghi H, Taherzadeh MJ. Synthesis and properties of a novel biosuperabsorbent from alkali soluble Rhizomucor pusillus proteins. Appl Microbiol Biotechnol. 2011;92:1171-7.

21. Aspevik T, Totland C, Lea P, Oterhals A. Sensory and surfaceactive properties of protein hydrolysates based on Atlantic salmon (Salmo salar) by-products. Process Biochem. 2016;51:1006-144.

22. Osman A, Gringer N, Svendsen T, Yuan L, Hosseini SV, Baron $\mathrm{CP}$, et al. Quantification of biomolecules in herring (Clupea harengus) industry processing waters and their recovery using electroflocculation and ultrafiltration. Food Bioprod Process. 2015;96:198-21010.

23. Souza Filho PF, Zamani A, Taherzadeh MJ. Edible protein production by filamentous fungi using starch plant wastewater. Waste Biomass Valoriz. 2019;10:2487-96.

24. Mahmoud A, Massoud M, Abdel-Motaal F, El-Zayat S. Tolerance and biosorption of manganese, iron and aluminum by five Aspergillus species isolated from freshwater. Catrina Int J Environ Sci. 2017;16:61-9.

25. Zafar S, Aqil F, Ahmad I. Metal tolerance and biosorption potential of filamentous fungi isolated from metal contaminated agricultural soil. Bioresour Technol. 2007;98:2557-611.

26. Hultberg M, Bodin H. Fungi-based treatment of brewery wastewater-biomass production and nutrient reduction. Appl Microbiol Biotechnol. 2017;101:4791-8. 
27. Hultberg M, Bodin H. Fungi-based treatment of real brewery waste streams and its effects on water quality. Bioprocess Biosyst Eng. 2019;42:1317-24.

28. Ferreira JA, Lennartsson PR, Taherzadeh MJ. Production of ethanol and biomass from thin stillage by Neurospora intermedia: a pilot study for process diversification. Eng Life Sci. 2015;15:751-9. 